\title{
EPIDEMIOLOGICAL AND DIAGNOSTIC STUDY OF AVIAN INFLUENZA VIRUS (H5N1) IN DOMESTIC BIRDS IN MISSAN PROVINCE
}

\author{
MRAISEL, A.CH. ${ }^{1}$; NAMA, M.A. ${ }^{2}$ and QASIM, M.J. ${ }^{3}$ \\ ${ }^{1}$ Department Zoonotic Disease, Nursing College, Missan University, Iraq \\ ${ }^{2}$ Department Medical Sciences, Nursing College, Missan University, Iraq \\ ${ }^{3}$ Department Medical Sciences, Nursing College, Missan University, Iraq
}

Received: 22 February 2016; Accepted: 20 March 2016

\begin{abstract}
ABSRACT
The aim of our study concerns with epidemiological and diagnostic study about prevalence of avian influenza virus in domestic birds depending upon recorded data of veterinarian hospitals in Missan province. so, the study (355) samples of blood and feces were taken from pigeons, (230) sample from chickens, (37) sample of domestic ducks and (9)sample of pet birds in period between (January -2006 to June-2006). The results observed there is infected with avian influenza virus subtype A (H5N1) consternated mostly in pigeons 40(11.26\%) and also found in domestic ducks $2(5.40 \%)$. Amara district was most common infected regions with bird flu in percentage 39(10\%), followed by Al-Mshreh 2(2.46\%) and Al-Kumit region 1(4.34\%). The infection was not recorded in domestic birds in another regions of Missan province.
\end{abstract}

Key words: Avian influenza virus, Domestic birds, Missan Province.

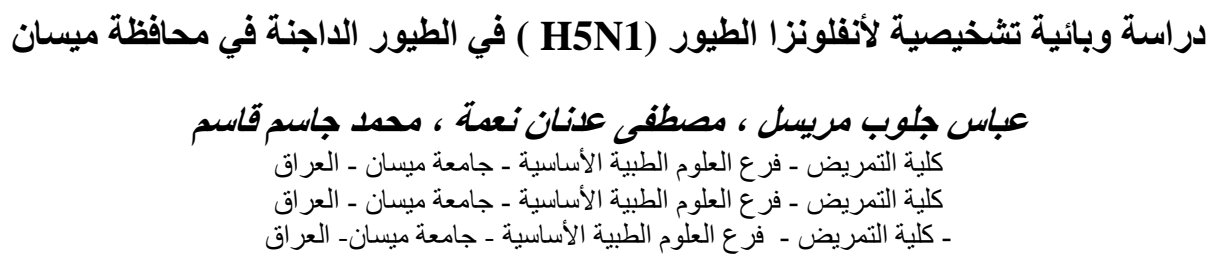

أجريت هذه الدر اسة لتحديد نسب الاصنابه بأنفلونزا الطيور وبالتعاون مع المستشفى البيطري في محافظة ميسـان و الاقضية و النو احي التي

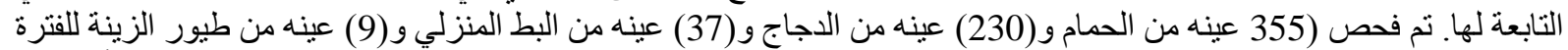

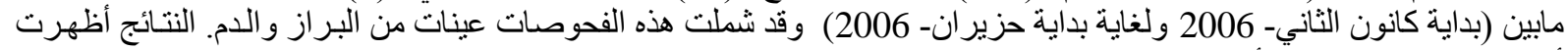

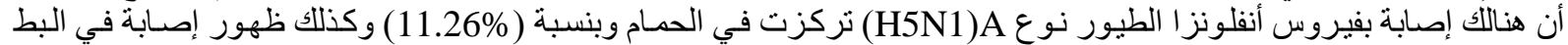

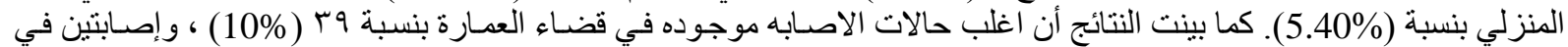

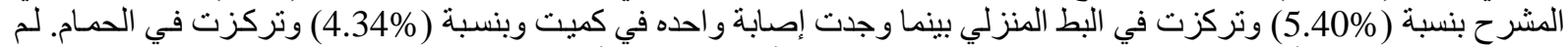

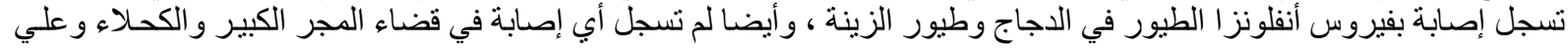

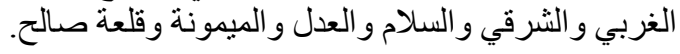

\section{INTRODUCTION} المقدمـة

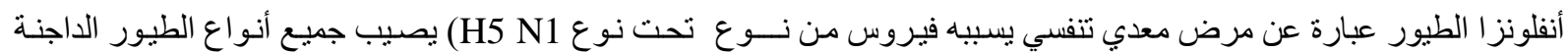

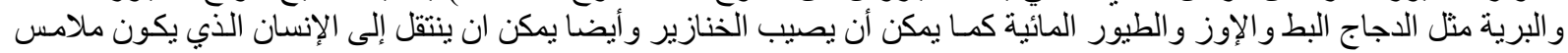
مباشر مع الطيور المصابة (WHO, 2006).

ظهر أنفونزا الطيور لأول مره في ايطاليا قبل أكثر من 155 سنة وكان يعرف بطاعون الطيور Fowl plaque، و اكبر وباء عالمي

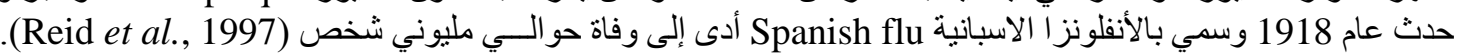
يتميز فيروس الأنفلونزا بقدرته الكبيرة على النحور (Mutation) في فترات زمنية قصبرة وبقدرته على تكوين عتر ات جديدة مدا

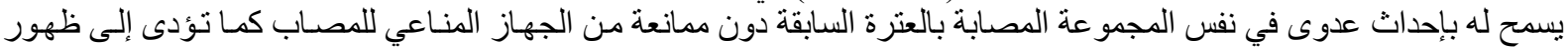

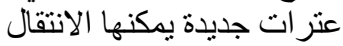




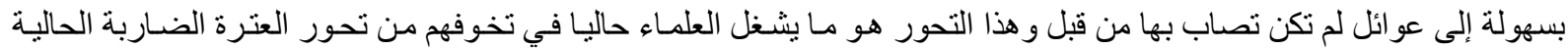

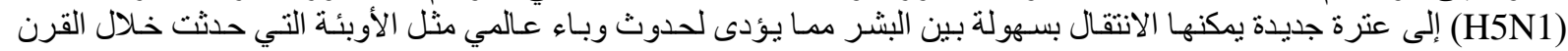

(Al-Shekly, 2003). (الماضي (H:)

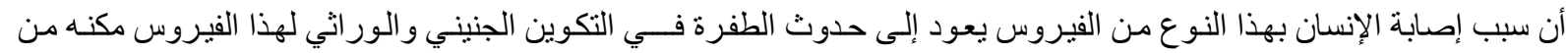

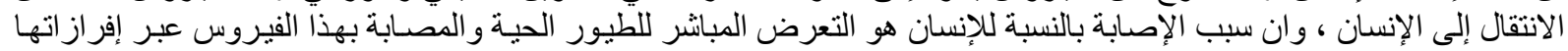

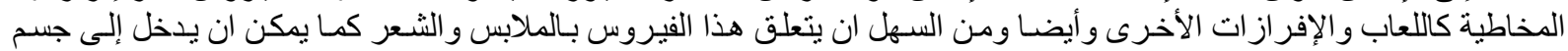

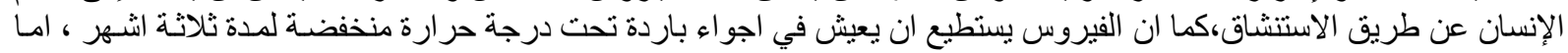

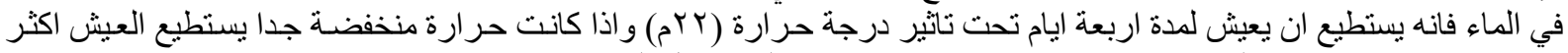

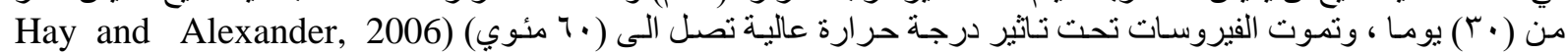

(Crosiers, 2005;

لا يوجد دليل و اضح حتى الآن يؤكد عملية انتقال المرض من بشر لأخر ولكن يوجد اثشتباه ببعض الحالات ولكن حصول الوبر الوباء العام

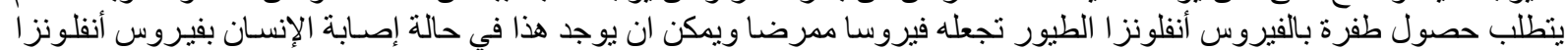

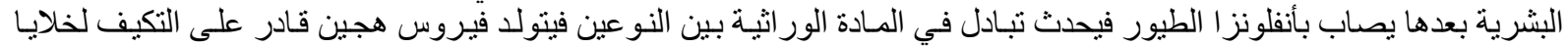

البشر والطيور (Rothsten, 2005; WHO, 2008)

التغير ات المرضية التي تحدث بالطيور المصابة تتميز بوجود احتقان شديد بملتحمة العين، تخزب تحت الجلد بمنطقتي الر أس و الرقبة

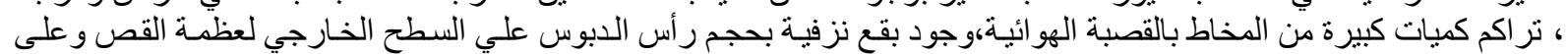

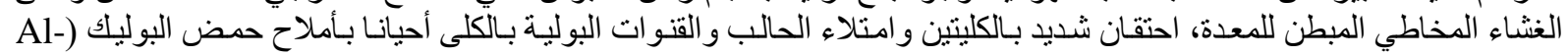

.(Shekly, 2003

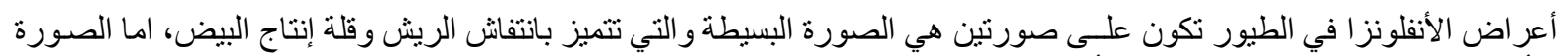

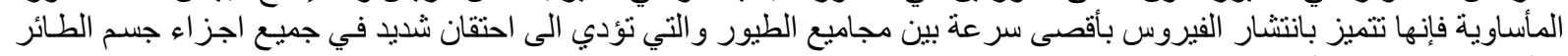

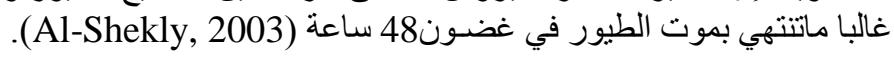

أما أعر اض المرض في الإنسان فهي نفس أعر اض الأنفلونزا العاديـة والتي تتميز بارتفاع درجة الحر ارة ور عشـة ورشح و إعباء،

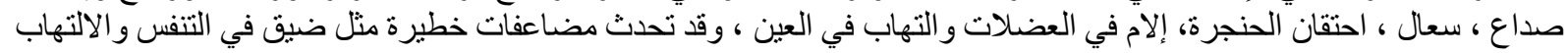
الرئوي الذي قد يؤدي إلى الموت (Hayen and Croisier, 2005; Walsh, 2006).

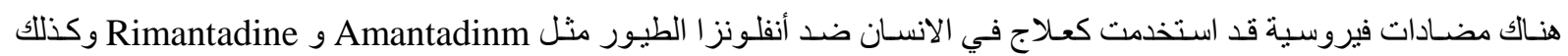

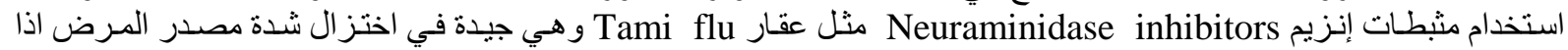
(He et al., 2007). استعملت خلال ^^ع ساعة من ظهور الاصنابة

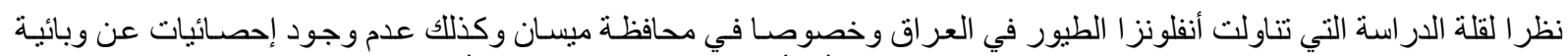

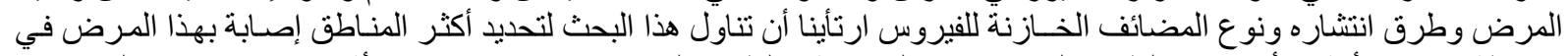

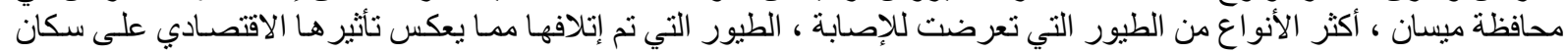
المحافظة ،كذلك تحديد هل حدثت إصابات بشرية.

\section{MATERIALS AND METHODS مواد وطر ائق العمل}

أجريت الدر اسة للفترة مابين (كانون الثاني- 2006 - حزير ان- 2006) بالتعاون مع المستشفى البيطري في محافظة ميسان من خلال

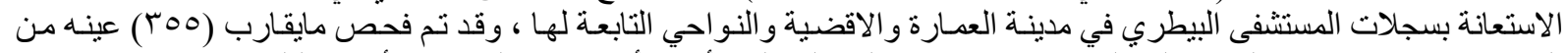

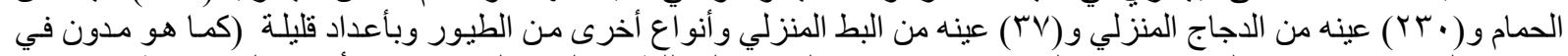

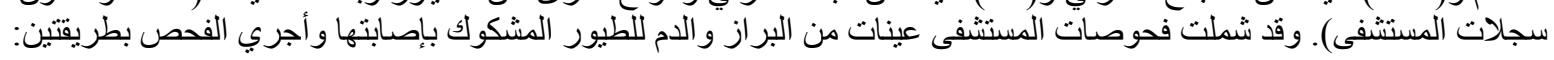

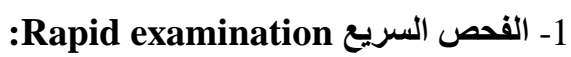

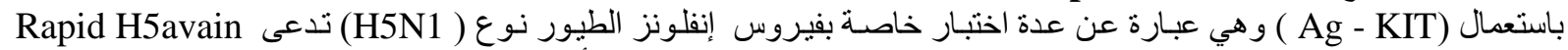

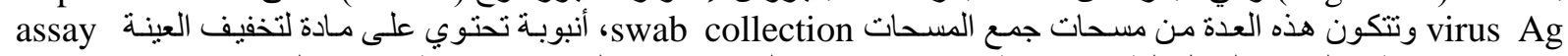

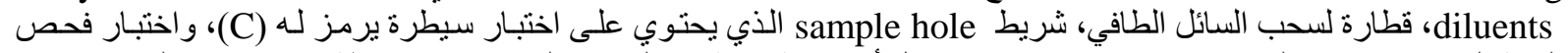

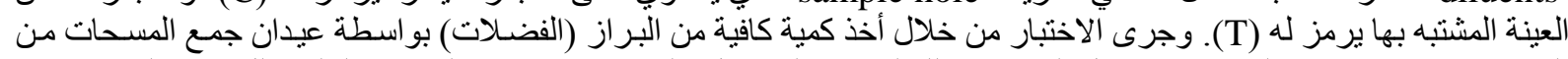

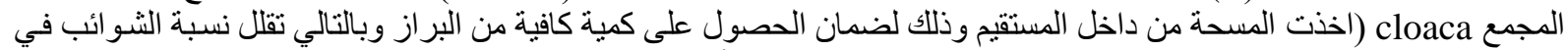

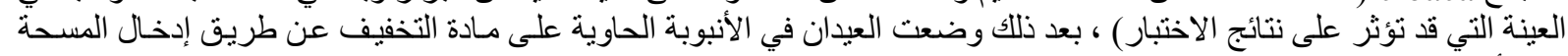

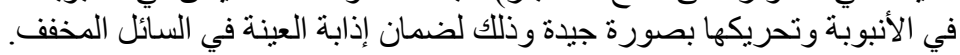




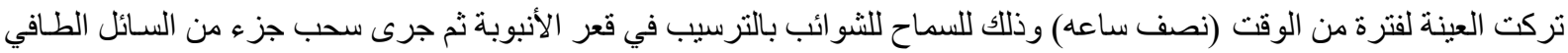

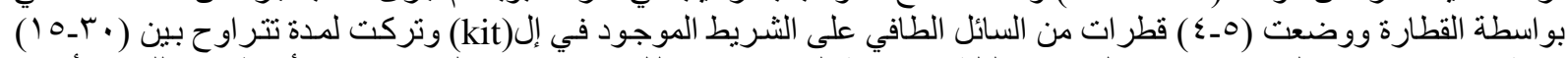

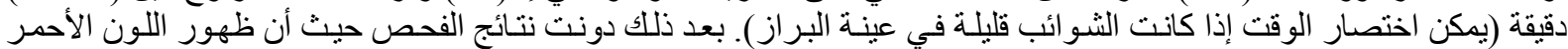

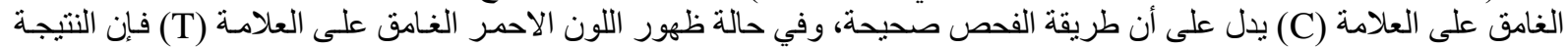
موجبة وعدم ظهور اللون الأحمر فإن النتيجة سالبة ولانية توجد إصلابة.

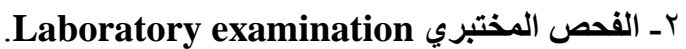

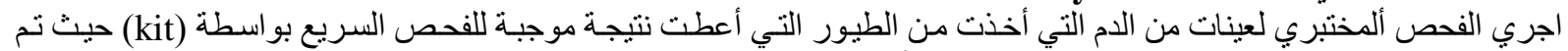

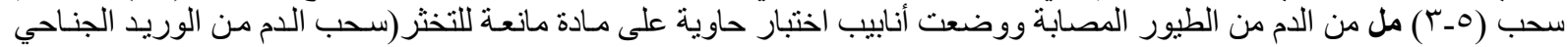
للطيور الكبيرة ومن القلب مبانشرة من الطيور الصغيرة).

وضعت هذه الأنابيب في جهاز الطرد المركزي وبسرعة . .. بـ دورة/ دقيقة ولمدة 10 دقيقة حيث تم فصل المصل عن باقي مكونات الدم أرسلت عبنات المصل إلى المختبر المركزي وذللك لإجر اء اختبار Enzyme Linked Immune Sorbet Assay) ELISA)

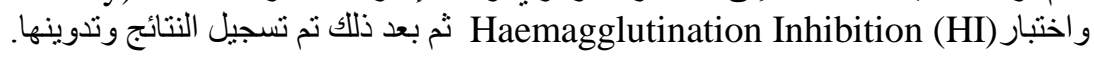

تم تحليل البيانات إحصي ي ائيا باستخدام اختبار مربع كاي Chi -Square عند مستوى معنوي ( 0.05 > P).

RESULTS

النتائَج

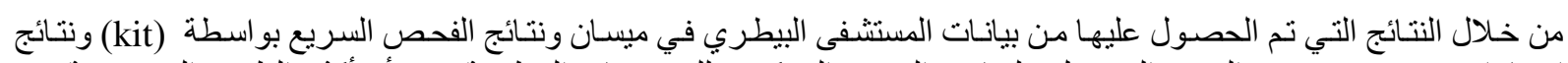

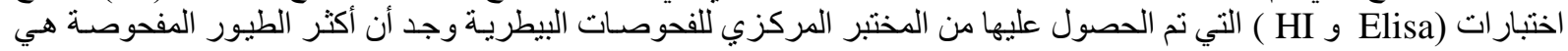

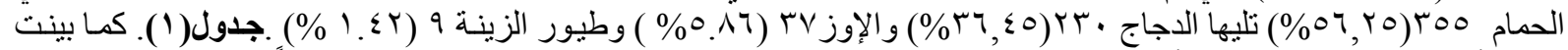

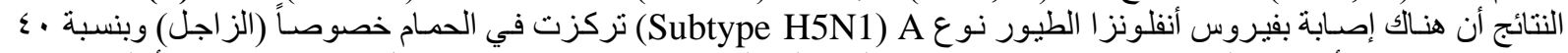

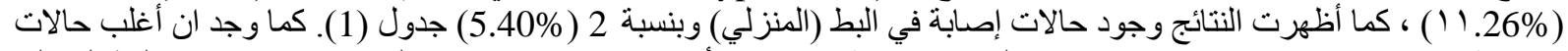

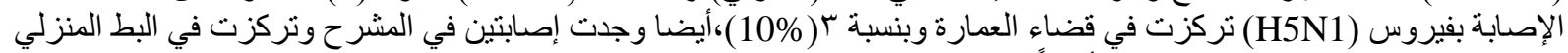

، و إصابة واحدة في ناحية كميت وكانت أيضاً في الحمام. ، شكل (1) (1).

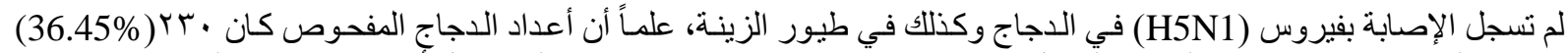

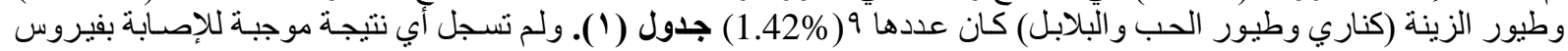

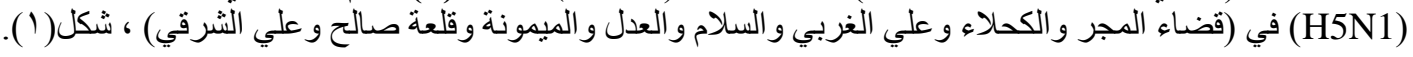

جدول ا : يمثل اعداد الطيور الدفحوصة ونسب الاصابة بانفلونزا الطيور (NO:631 ).

\begin{tabular}{|c|c|c|c|c|}
\hline نسبة الإصابة & الطيور المصابة & النسبة لعدد الطيور الكلي & أعداد الطيور & 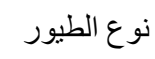 \\
\hline $11.26 \%$ & 40 & $56.25 \%$ & roo & 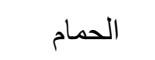 \\
\hline $0 \%$ & 0 & $36.45 \%$ & rt. & الدجاج \\
\hline $5.40 \%$ & 2 & $5.86 \%$ & rv & البط المنزلي \\
\hline $0 \%$ & 0 & $1.42 \%$ & 9 & طيور الزينة \\
\hline $16.8 \%$ & 42 & $100 \%$ & וT & المجموع \\
\hline
\end{tabular}




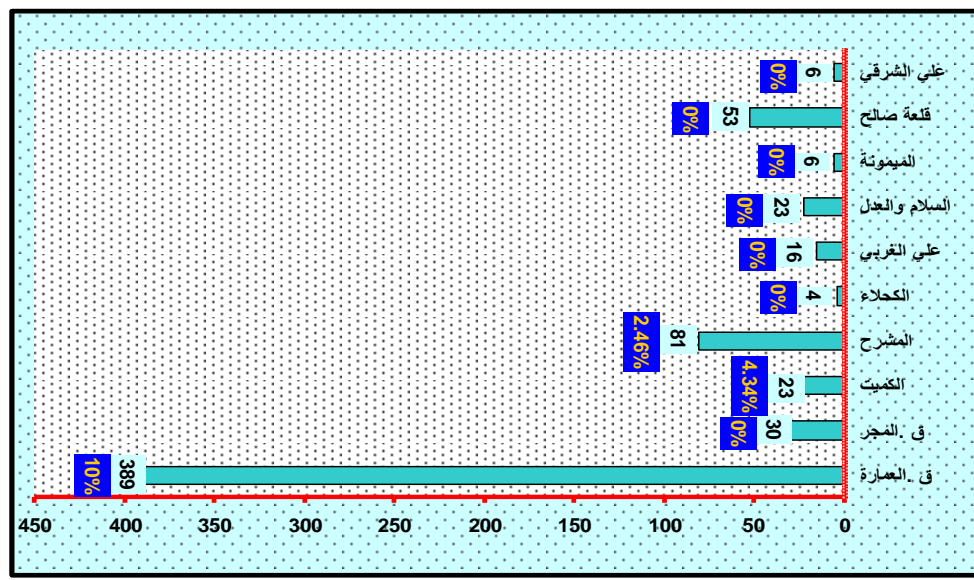

شكل ( ) يمثل نسب الإصابة بفيروسH5N1 للطيور المفحوصة مبوبة حسب المناطق التي جمعت منها (NO:631).

\section{DISCUSSION \\ المناقثة}

من خلال نتائج البيانات التي تم الحصول عليها من المستشفى البيطري في ميسـان و التي تضمنت نتائج الفحص السريع (kit test)

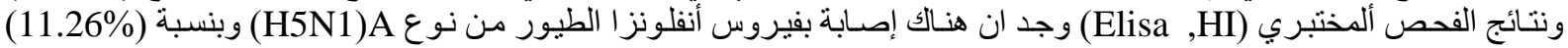
تركزت في الحمام (5.40\%) في البط المنزلي.

من خلال التشخيص السريري وجد ان الحمام المصاب لا تظهر عليه أية أعر اض مرضية سوى وجود إسهال (مائل للأخضر ) وكذللك

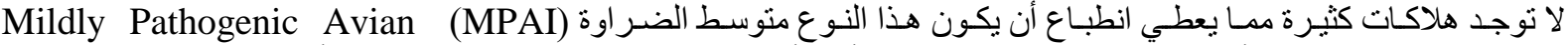

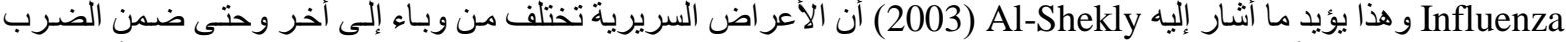

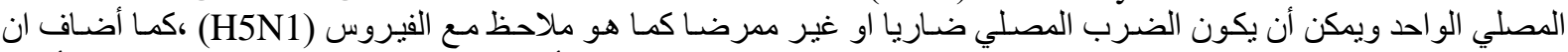

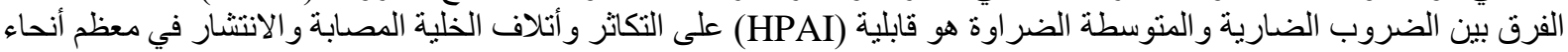

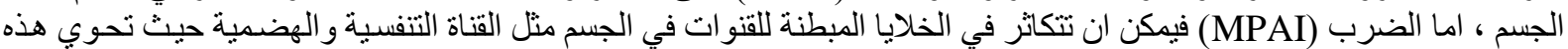

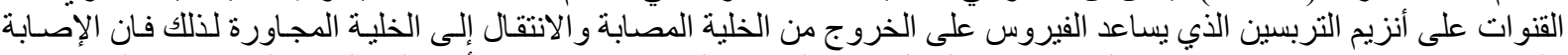

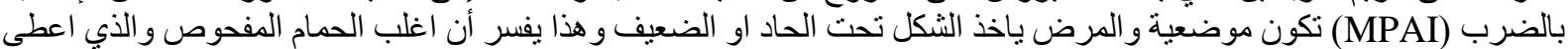
نتيجة موجبة للفحص السريع ويكون لون البراز مائل إلى الأخضر.

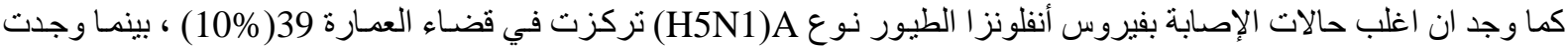

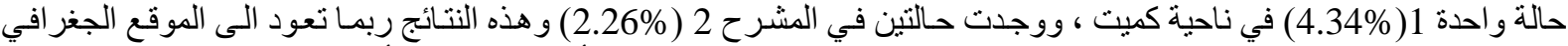

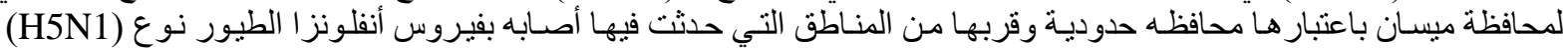

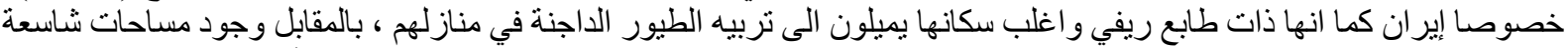

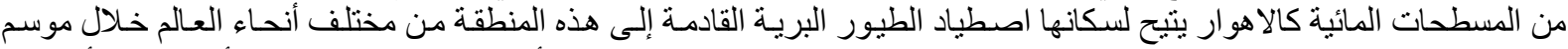

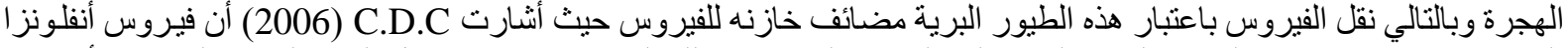

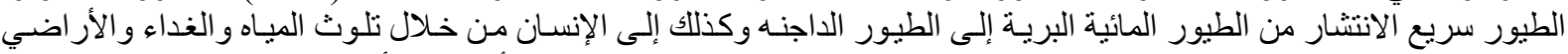

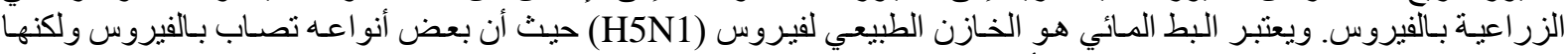

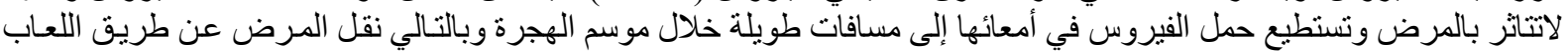

لم تسجل إصابة بفيروس (H5N1) في الدجاج وكذلك في طيور الزينة (كناري ـ طيور الحب ـ البلابل) وهذا قد يعطي حقيقة علميـ

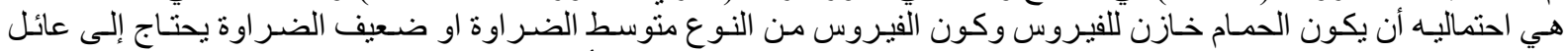
(مضيف وسطي) من نو عه لكي يصبح ضاري جدا ويستطيع الانتقال بسهوله إلى الأنو اع المختلفة من الطيور ويسبب هلاكها.

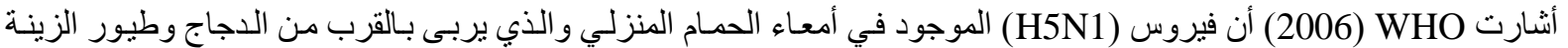

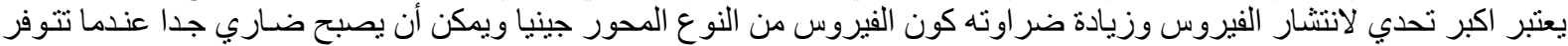

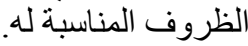

لم تسجل أي نتيجة موجبه للإصـابة بفيروس (H5N1) في المجر الكبير و الكحلاء و وقضـاء علي الثشرقي و الغربي و السـلام و العدل

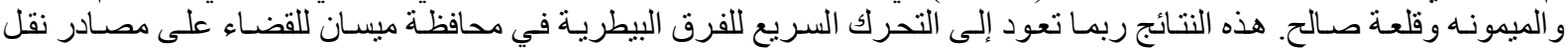


الفيروس و المضائف الخازنة له ، وكذلك إيقاف تداول بيع الطيور البرية والداجنة بين المناطق المختلفة من المحافظة ، و عدم ارتياد حقول الدو اجن و أسواق بيع الدجاج الحي وطيور الزينة (المستشفى البيطري التصال شخصي).

لم تظهر أصابه بشريه بأنفلونزا الطيور من نوع (H5N1) الا حاله واحدة كان الاشتباه بإصابتها بالمرض وهو الحد مر مربي الحمام الذي

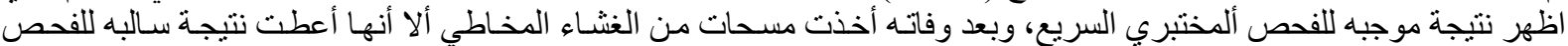
ألمختبري.

منظمة الصحة العالمية WHO WO (2006) أثنارت انه من خلال متابعه أمر اضية فيروس (H5N1) في الإنسان وجد أن الفيروس يميل

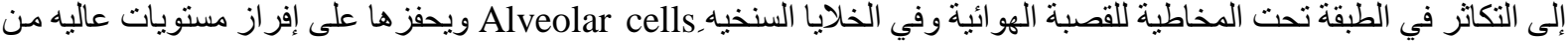

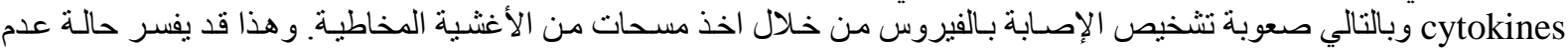
ظهور نتيجة موجبة عند اخذ مسحات من القصبة الهو ائية للشخص الشئس المتوفي.

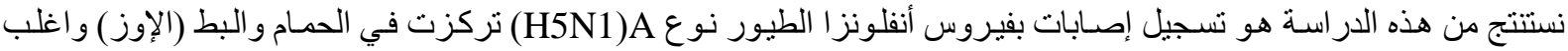

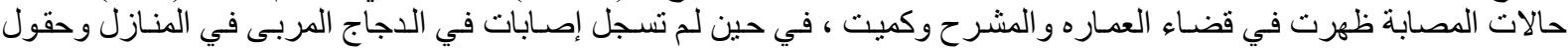

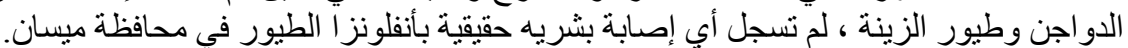

لذللك يتطلب اتخاذ عدة إجر اءات منها التعمق بدر اسة وبائية مرض أنفلونز ا الطيور في محافظة ميسان ، تحديد المضيف الخازن و الذي

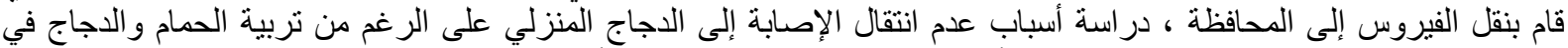

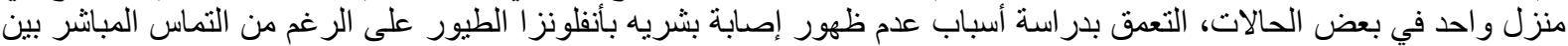
مربي الحمام والطيور الديفر المصابة.

\section{REFERENCES}

المراجـع

Alexander (2006): An overview of the epidemiology of avian influenza. Vaccine. 25: 5637-5644.

AL-Sheckly, F.A. (2003): Poultry disease. $2^{\text {th }}$ Ed. Atles-Baghdad. P: 288-296.

C.D.C. (Central Disease Control). (2006): Prevention of avian influenza :current situation. www. CDC.gov/avian out breaks/current. htm.

Hayden, F. and Crosiers, A. (2005): Transmission of Avian influenza viruses between humans. Jor. Infection. Dis.192: 1311-1314.

He, G.; Qiao, J. and Dong, C. (2007): Amantadine resistance among H5N1 avian influenza viruses isolated in north china. Antiviral research. 77(1): 72-76.

Reid, AH.; Kraff, AE.; Bijaaard, KE. and Fanning, TG. (1997): Initial genetic characterization of the 1918 "Spanish" influenza. Virus. Science; 275: 1793-6.

Rothstein, J. (2005): Environmental factors Affecting the spread of Bird Flu. F.E.S.S. www.fessglobal.org.703: 560-590.

Walsh, T. (2006): Avian flu: preparing for a pandemic .http://www.marsh .com .Vol V. Issue I.

WHO (World Health Organization). (2006): Information about Avian influenza (Bird Flu) and avian Influenza A (H5N1) Virus. www.who.int/csr/disease.htmal.

WHO (World Health Organization). (2008b): Disease out break news . who. Geneva, Switzerland. Available online at: http://www. who. Int /csr/don/en. 